\title{
Noncarious Cervical Lesions as Abfraction: Etiology, Diagnosis, and Treatment Modalities of Lesions: A Review Article
}

\author{
Ahmed Mohammed El-Marakby ${ }^{1,2}$, Fuad Abdo Al-Sabri ${ }^{3^{*}}$, Sahar A Alharbi ${ }^{4}$, Shahad M Halawani ${ }^{4}$ and Mehaf T bin Yousef ${ }^{4}$ \\ ${ }^{1}$ Assistant prof at Department of Restorative Dental Sciences, AL-Farabi College for Dentistry and Nursng, Riyadh, KSA, Saudi Arabia \\ ${ }^{2}$ Lecturer at Department of Operative Dentistry, Faculty of Dentistry, Al-Azhar University, Cairo, Egypt \\ ${ }^{3}$ Associate Prof at Department of Operative Dentistry, Faculty of Dentistry, Thamar University, Dhamar, Yemen \\ ${ }^{4}$ AL-Farabi Colleges for Dentistry and Nursing, Riyadh, KSA, Saudi Arabia
}

*Corresponding author: Fuad Al-Sabri, Department of Operative Dentistry, Faculty of Dentistry, Thamar University, Dhamar, Yemen, Tel.: +00967-777225534; E-mail: alsabrifuad@yahoo.com

Recieved Date: April 4, 2017; Accepted Date: May 25, 2017; Published Date: May 31, 2017

Copyright: (c) 2017 El-Marakby AM, et al. This is an open-access article distributed under the terms of the Creative Commons Attribution License, which permits unrestricted use, distribution, and reproduction in any medium, provided the original author and source are credited.

\begin{abstract}
Abfraction may be defined as V-shaped or wedge shaped defect at the cervical region of a tooth with different clinical appearances mostly seen as angular notch like depressions on the facial surface of tooth structure at the junction of tooth and gingiva, this may be due to flexure of the cusp leading to mechanical overloading and may also be accompanied by pathological wear such as regressive alterations of teeth. Recent research on non-carious cervical lesions (NCCL) suggests that abfraction is also due to multifactorial etiology. The different types of cervical lesions in the human population is determined by their biological, chemical and behavioural factors. There are two school of thoughts regarding the etiology of abfraction among the population. The first school of thought argues that tooth brushes with other artificial forces may be the causative factors and the second school considered that some internal physiological forces as the causative factors. The second school of thought even though do not provides complete explanation, yet provides a significant role of this cervical lesions. The present review focuses on the etiology and all available treatment plan strategies of non-carious cervical lesions.
\end{abstract}

Keywords: Abfraction; Non-carious cervical lesions; Cervical wear; Dentin hypersensitivity

\section{Introduction}

During the last two decades of the previous century, the terms "attrition", "abrasion" and "erosion" are discussed in such a manner that the etiology and treatment planning seems to be confusing. Furthermore, at the same time, one more recent introduction of the term "Abfraction" to designate stress induced non-carious lesions has added more perplexity rather than to resolve the dilemma of NCCL fully [1]. Braem et al., described the Abfraction as micro-substance loss of the tooth structure in the cervical regions of the teeth wherein the flexure leads to micro-level fracture of the enamel rods and cementum surface then affecting the dentinal tubules leading to wedge shaped defect in the areas of stress concentration [2]. According to that definition, Abfraction is 'to break away'. Grippo in 1991 was the first one to describe the result of biomechanical loading of forces leading to pathological loss of enamel and dentin and coined the term 'abfraction' [3]. Non-carious cervical lesions and stress corrosion are the other terms suggested for this process [4]. Abfraction merely signify as tooth structure loss at cement-enamel junction [5]. Abfraction, attrition, erosion is due to normal and abnormal or pathological wear of the dental tissues [6]. Depending on the type and severity of the etiological factors involved, the clinical appearance of cervical lesions varies [7]. Stresses caused by occlusal forces is the main etiological factor for noncarious cervical lesions. Tensile stress resulting from malocclusion and forces of mastication was initially thought as the primary factor in NCCLs [1] and later these lesions were termed as abfraction lesions [3]. Even though some authors believed that occlusal forces are considered as the main cause of abfraction, it's aetiology remains poorly understood and debatable $[8,9]$. At present, considering a single factor to be the cause of NCCLs is not correct, instead the recent evidence suggests that NCCLs are multifactorial and depends on the patient factors for the various degrees of tooth structure loss [10-13]. Based on the dentist's belief on the effectiveness and other alternative restorative interventions in regard to durability and minimal loss of tooth structure is still questionable issue in restorative dentistry and there is no evidence based guidelines present in literary works to help dentists to know how and when these tooth defects can be restored $[14,15]$. The present review helps to provide a clear and deep understanding of this complex situation on where abfraction lesions stand in research and practice today by presenting the new knowledge and different treatment modalities for these lesions.

\section{Causes and Theories of Abfraction}

Since 'abfraction' is still a debatable theory as there are many reasons on what causes these lesions [16]. Abfraction means "to break away", a term copied from the Latin language words "ab", or "away" and "fractio" [3]. One study suggests that Abfraction is due to flexure in the cervical area of tooth from the occlusal compressive forces and tensile stresses leading to microfractures of enamel and dentin at the hydroxyapatite level in turn resulting further fatigue and deformity of tooth structure [17-19] and some researchers even proposed that the occlusal forces on the tooth from chewing and swallowing leading to concentration of stress and flexion in the area where the enamel and cementum meet $[3,9]$, as the etiological factor of Abfraction $[8,20]$. The bonds in the enamel rods tend to break down and either fracture due to stress concentration or due to flexion in the cervical area 
leading to erosion or abrasion and later researchers who once thought as occlusal forces as the etiological factor $[3,8,9,20]$, later added, such as abrasive agents like tooth brushes, abrasive paste and or erosion also as one of the etiological factor [21].

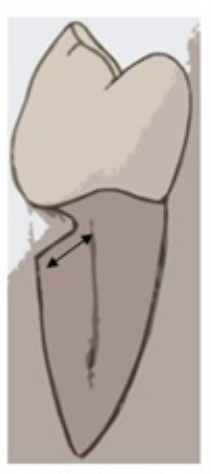

Wedge shaped abfraction lesion

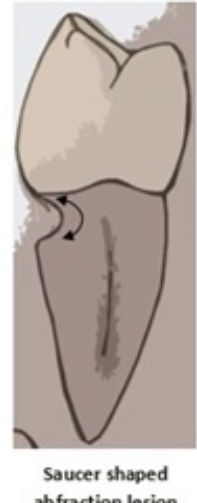

abfraction lesion

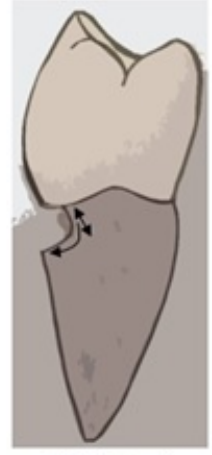

Mixed shaped abfraction lesion
Figure 1: Clinical shapes of abfraction lesions.

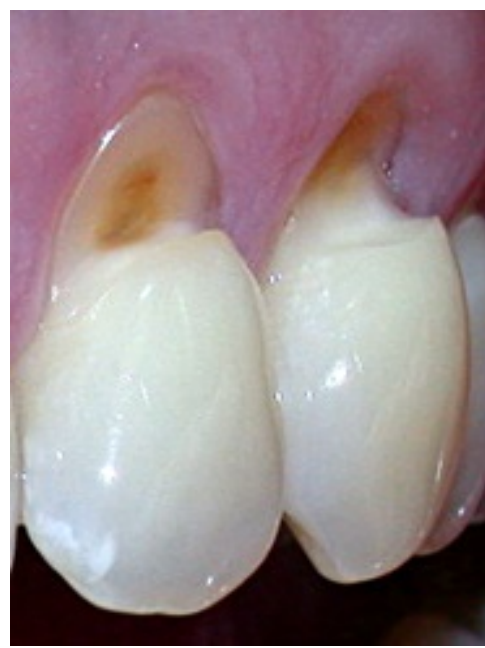

Figure 2: Deep abfraction notch.

The Abfraction lesions are associated with thin structure of the enamel rods with low packing density of Hunter-Schreger bands (HSB) at the cervical area [22]. Many experimental studies are performed to replicate the stress distribution in the cervical region of teeth $[17,18,23,24]$. Bioengineering studies have discovered the association between wear at the cervical region and occlusal stresses by employing finite elemental analysis or photo-elastic methods [23,25,26]. Moreover, very few clinical studies have not provided enough evidence on the relation between Abfraction lesions and occlusal stresses [27-29]. Some researchers believed that in a non-ideal bite leads to creation of stresses in the cervical region of the teeth [9]. Other research findings suggested that chewing and swallowing may not create sufficient stresses on the teeth and flexion to cause abfraction lesions [8], but a person having deleterious oral habits like bruxism create sufficient stresses to develop abfraction lesions at the cervical regions [8]. It is noticed that NCCLs are common in those individuals who grind their teeth as the forces acting are of long term duration and greater quantity $[16,21]$.
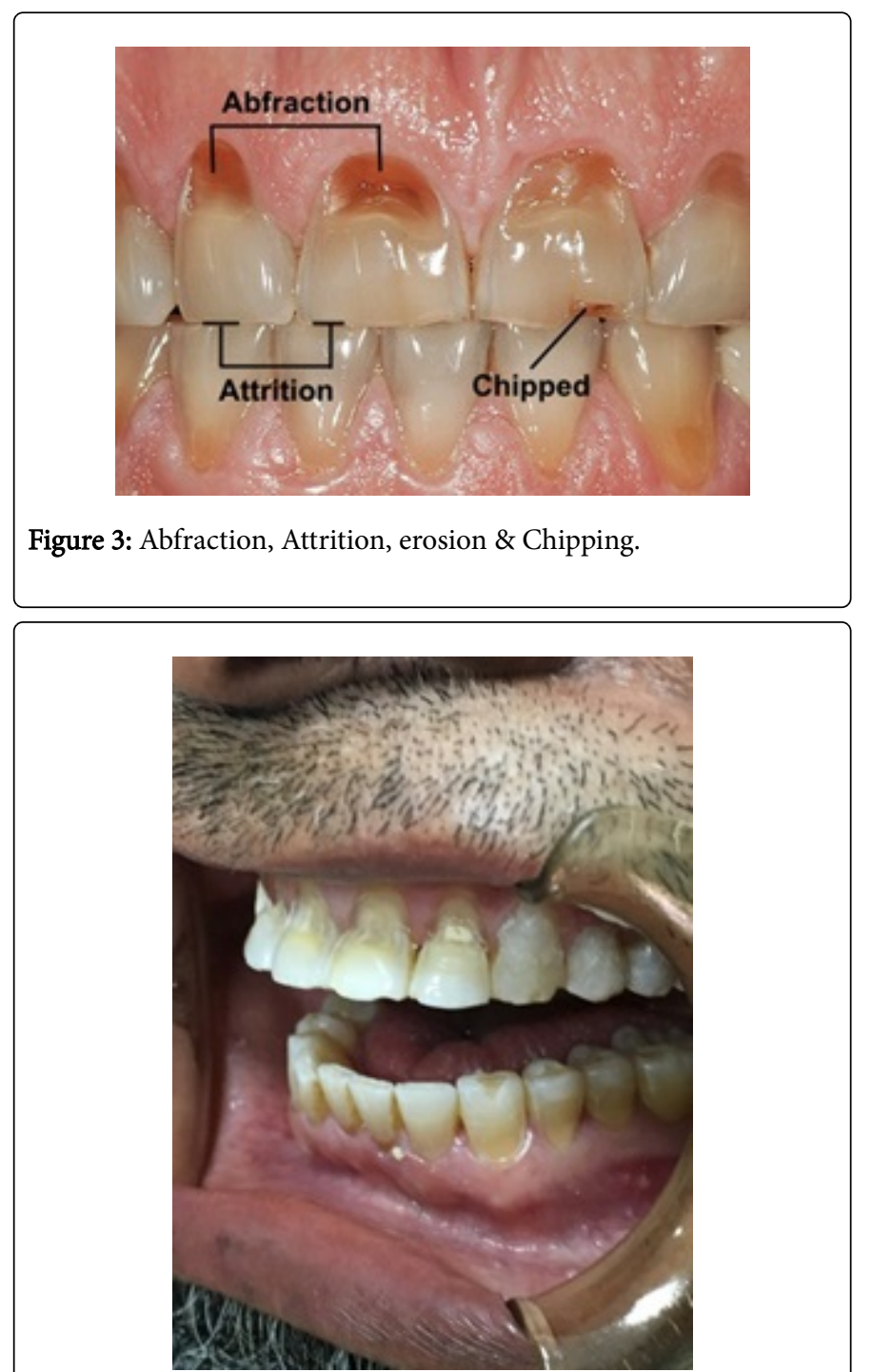

Figure 4: Generalized cervical non carious lesion; an elderly patient exhibiting NCCLs in the whole dentition (Abbreviation: NCCL, noncarious cervical lesion).

In conclusion, it is observed that there is weak relation between the occlusal factors and the NCCLs [3]. In clinical practice, not all patients with abfraction lesions present occlusal wear (bruxism or clenching) and vice versa [28]. The clinical relationship between the incidence of occlusal wear and cervical demineralization with NCCL dimensions [30] has been reported using optical coherence tomography, in which the dentin demineralization promotes the formation of NCCLs from an early stage, whereas occlusal stress is an etiological factor that contributes to the progression of these lesions [30]. Group of another investigators also mentioned that NCCLs are not due to occlusal forces at the CEJ region but because of tooth brushes along with abrasive tooth pastes which leads to NCCLs $[8,16,20]$. Another theory states that these lesions are found above the cemento- enamel junction (CEJ) [31-33] which serves as differentiating criteria to diagnose other type 
of cervical lesions. Hence the term abfraction is yet to be well justified (Figures 1-4).

\section{Diagnosis of Abfraction}

Like any other clinical situation, the diagnosis of abfraction, is usually considered using medical and dental history associated with clinical examination of an individual that plays an important role in the treatment of these cervical lesions. These lesions are multifactorial origin and have many contributing factors which change over time and it is necessary that these potential factors should be evaluated while examining a patient with these lesions. The individual should be also evaluated for any gastro-esophageal reflux disease, eating disorders, and dietary contributors, occlusion, parafunction and oral habits including occupational and ritual behaviours [34]. The interaction between chemical, biological, and behavioral factors is critical and helps to explain why some individuals exhibit more than one type of cervical wear mechanism than others. Diagnosis of these lesions can be entailed by the patient related factors and the most common clinical symptoms associated by these lesions, which in turn help in formulating a strategic treatment plan to the individuals. The process of erosion, which is often associated with diagnosis of non-carious cervical lesions, is defined as the progressive loss of dental hard tissues due to the acids released by non-bacterial intrinsic or extrinsic sources. Other terms bio-corrosion has also been introduced to include all forms of biochemical and electrochemical degradation (As seen in Figure 4) [9]. Regurgitation is defined as an involuntary process as a complication of gastrointestinal problems, or be patient-induced as in anorexia nervosa or bulimia. Dietary erosion results due to high intake of foods or drinks having a variety of acids, from citrus fruits, juices (citric acid), soft aerated drinks, wine and other carbonated drinks (carbonic acid and other acids). It's also been stated that bio-corrosion or erosion can occur by the regular use of acidic mouth rinses [9]. It is also noticed as unusual phenomena in individuals exposed to industrial work environment leading to exposure of industrial acidic fumes or droplets (e.g., battery factories), and noticed in activities like swimming in chlorinated pools, etc. [35]. Every clinical appearance of abfraction appears to be dependent on the type and severity of the etiological factors involved [7]. As seen in Figure 5 that NCCLs is of multifactorial nature depicting the upper premolar with advanced abfraction lesion in a patient presenting other types of cervical lesions. The descending order of prevalence of NCCLs is incisors, premolars, canines and molars $[11,14]$. Mandibular premolars are affected by NCCLs more often and more severely than maxillary premolars [11]. In severe cases the whole dentition is affected with NCCLs such as erosion wherein aging is associated with other pathological factors, as shown in Figure 4. These Abfraction lesions are primarily seen on the buccal surfaces and are typically V-shape or wedge like lesions with clearly demarcated internal and external line angles [23]. Some lesions are also noticed as C-shaped lesions with rounded floors or mixedshaped lesions with flat, cervical, and semi-circular occlusal walls [36]. Sometimes the contributing factors leading to erosion or abrasion can also alter the clinical manifestations of these lesions by making the blunt angles and broader outlines and more saucer-shaped lesions. Moreover, abfraction lesions may appear deeper than wider depending upon the stage of progression and related etiological factors Figure 1. Multiple abfraction lesions seen overlapping on one another, observed in Figure 6, seem to appear due to various forces producing tensile stress $[1,12,23]$. Occasionally, abfraction lesions that are noticed below gingival margins, where the tooth brush or other devices can't reach, believed to have biomechanical loading forces as a major contributing factor [12]. A single tooth in a quadrant with an abfraction lesion is an indication that occlusal stress might be the primary contributing factor [12].

Upon examination, it is noticed that NCCLs caused by vomiting typically affects the palatal surfaces of the maxillary teeth, but this condition can also be due to other contributing factors like dietary acids. Individuals suffering from medical conditions and are on medications like anti-sialagogues have reduced rate of saliva secretion leading to erosive effect on tooth surfaces. Abfraction lesions are more prevalent in the adult age population of 40 years old affecting mainly the premolar teeth. On observation, the severity of occlusal and cervical wear increases with age and therefore considered as natural physiological processes. Due to the wear on the occlusal and cervical surfaces of tooth, the defence mechanisms are activated leading to formation of reactionary and reparative dentin and helps in obstructing the exposed dentinal tubules by the deposition of minerals $[3,6,12,13]$. The main context in this reparative process is that the odontoblastic cells are active throughout the vital life of the tooth and if they are damaged or destroyed, the mesenchymal precursor cells in the pulp help to differentiate themselves to help in formation of minerals to block the exposed the dentinal tubules [37]. Understanding the physiologically dynamic process of changes noticed in the cervical regions of the tooth due to age related factors, unnecessary restorative interventions can be avoided [38]. The NCCLs index given by Smith and Knight uses a scale from 0 to 4 , where $0=$ no change in contour, $1=$ minimal loss of contour, $2=$ defect $1 \mathrm{~mm}$ deep, $3=$ depth of defect between $1 \mathrm{~mm}$ and $2 \mathrm{~mm}$ and $4=$ depth of defect $2 \mathrm{~mm}$ or exposure of secondary dentin or pulp [39]. Another index for NCCLs has been proposed which not only includes depth of lesion but also the width and angle between the lesion and the occlusal and cervical walls are quantified from 1 to 3 [40]. As new technology is advancing like digital dentistry, CAD/CAM, the method to conclude the diagnosis and monitoring of NCCLs activity will be improved and more clear understanding of the lesions will be notified.

\section{Treatment Modalities of Abfraction}

Many treatment strategies have been proposed to treat these NCCL lesions. Dentists are of different opinion in managing these lesions, which is attributed to the lack of enough clinical evidence among the dentist's in managing these type lesions [41-43]. This decision to propose a proper treatment depends mainly on the patient factors and the severity of the problem. Preventive interventions starts with individual counselling for changes in patient's attitude, such as diet, brushing method, protective night guards to avoid clenching or bruxism, supplementary use chewing gums to increase salivary flow rate and/or to seek therapy or medical attention if there is a potential, intrinsic medical or mental condition. Other treatment options include the following: monitoring the progression of lesions, adjusting occlusal, splint therapy, techniques to alleviate hypersensitivity, restorations, and root coverage procedures in combination with restorations.

\section{a- Only observation and follow up (Monitoring the lesions)}

The decree to monitor abfraction lesions rather than to intervene restoratively should be related to the patient's age and how these NCCLs compromises in both function and tooth vitality. Generally, physiological cervical wear is a chronic process. Wear of tooth is generally considered as physiologic process and age related factor and is usually not said as risk for fracture or pulp exposure and is seen through patient's lifetime without operative intervention. However, if 
the tooth wear negatively involves with the long-term prognosis of the tooth, operative treatment may be required. In most cases, there is no complaint from patients with abfraction lesions since lesions are painless and do not affect the esthetics of individual. In such conditions, it is generally advisable to monitor these lesions at regular interval with no operative intervention, where no serious clinical manifestations observed and where the lesion depth is shallow $(1 \mathrm{~mm})$. The monitoring of these lesions activity can be performed for every 6-12 months and during regular oral hygiene visits.

\section{Occlusal Correction and Adjustment}

As many researchers postulated the relation between occlusal stress and abfraction lesions, the occlusal adjustments like altering the cuspal inclines, reducing heavy contacts and removing the premature contacts have been suggested to improve the conditions associated with abfraction. However, there is no clinical evidence to support this type of clinical interventions to treat cases of abfraction lesions. Altogether, inappropriate occlusal adjustments may lead to caries initiation, occlusal tooth wear and dentinal hypersentivity. In order to avoid and control inappropriate occlusal forces, night guard devices has been advised to minimize the initiation of NCCLs. $[15,31,44]$.

\section{Desensitization of Dentin Hypersensitivity}

Dentinal hypersensitivity is a response to stimuli caused by short, sharp pain. The temporary symptom of early stages of abfraction lesion is dentin hypersentivity. Since Abfraction is a long standing or chronic lesion it is associated with natural repair or dentinal remineralization which will reduce tooth sensitivity gradually. In some cases the repair or remineralization is insufficient, and the sensitivity persists, in those cases the exposed dentin should be treated to relieve discomfort to the patient $[45,46]$. Various cost-effective and non-invasive treatments like application of desensitizers, fluoride varnishes on to the exposed dentinal tubules or use of desensitizing toothpastes containing silver diamine fluoride or potassium nitrate, which might partially or completely occlude the open dentinal tubules [47-49]. Different types of lasers have also been introduced as an alternative option for treating tooth sensitivity, but their clinical efficacy is unclear [50].

Other non-invasive treatments include temporary sealants such as Varnishes and Dentin bonding agents. In extreme cases of Hypersensitivity unresponsive to non-invasive procedures, a restoration might be required. Restorations of Resin-based composites (RBCs) and Resin-modified glass ionomer cement (RMGIC) showed significant reduced dentinal hypersensitivity initially, but reported increased sensitivity of the restored tooth to air and cold when evaluated after 6 months [51].

\section{Restorative Treatment}

Benefits of restorative dentistry in treating NCCLs is debatable [42]. A predisposition to failure of restorations placed in NCCL area is observed because of the etiology of the lesions. The failure of restorations in the areas of these lesions is attributed to, moisture contamination, improper access to subgingival margins $[8,41]$, and inability to treat sclerotic dentin [43]. The factors affecting the retention and clinical performance of NCCL restorations may be the occlusal loads $[15,52,53]$, quality of dental substrates and mechanical properties of restorative materials [54]. It is observed that even though the NCCL lesions are treated using restorative procedures, there is no evidence that the progression of NCCL lesion is arrested, hence these restorative treatments cannot used as a preventive treatment strategy to stop the propagation of lesion. So the restorative treatment in case of NCCL are planned only if any of following conditions are met:

- Presence of active caries along with Abfraction lesions; the assessment of risk factors for caries initiation are determined initially before concluding with appropriate treatment plan,

- The lesions located on the cervical margins and or located subgingivally and impede the plaque control are at increased risk of caries and periodontitis,

- The tooth which is damaged with one or two surface defect, loss of integrity of teeth, and or pulp is near to exposed,

- Continuous hypersensitivity due to exposure of dentin and in which cases the non-invasive treatment options have not shown successful results,

- Prosthesis and

- Patient demand for aesthetics.

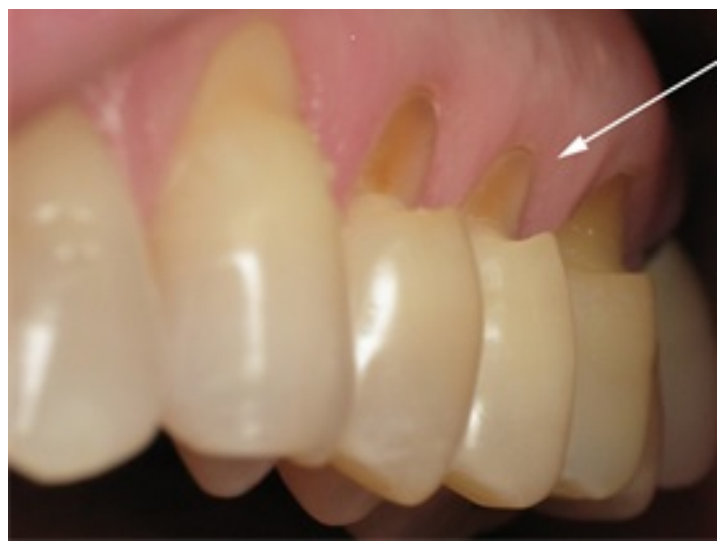

Figure 5: Abfraction lesion at the gum line. A typical abfraction lesion in a patient with multiple types of NCCLs. [Notes: Arrow shows the second upper premolar with the typical lesion (Abbreviation: NCCL, noncarious cervical lesion)].

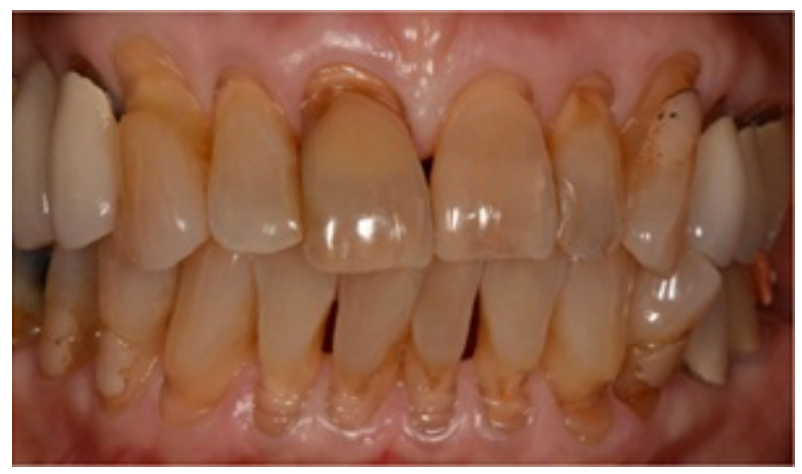

Figure 6: Generalized Abfraction. Abfraction lesions of different shapes, widths, and depths, Characteristic of their different stages of progression.

In cases where the abutment tooth of a planned removable partial denture has abfraction lesions, then the resin bonded composite restorations should be the esthetic treatment of choice for dealing these 
type of cases, though the demerits would be accounted during removal and insertion of the prosthesis, which may result in wear of the restoration during prolonged use. As much as possible the restorations of NCCL should be restored with minimally invasive method. If there is a need for placement of restoration, NCCLs should be restored as minimally invasive as possible. The retention of the cement is also an important criterion while planning for a restorative NCCL procedure. The factors related to restorative retention are location of tooth, age of patient and occlusion [55]. The mechanical properties of the restorations dealing with NCCL should have low young's modulus, good adhesive properties, wear resistance and ability to withstand acid dissolution $[42,56]$. In all the restorative systems available in dentistry, the most preferred is adhesive systems, specifically RBCs due to their esthetic results and more conservative approach [57]. Other material of choice are GICs, RMGICs, and the lamination technique of GIC/ RMGIC with RBC have been advocated for NCCL restorations $[54,58]$ but these restorations are not frequently used and these restorations on NCCL are supported by only a few long-term clinical studies $[55,59,60]$. In addition, the restorative materials like glass ionomer and self-etch adhesive restorations have a standard effectiveness in bonding (Figures 5 and 6) [57].

\section{Conclusion}

The abfraction lesions like any other NCCLs have a multifactorial etiology. The combined result of different etiological factors and the patient related factors have led to further initiation and progression of the abfraction lesions which differ among themselves within their clinical appearances. Proper recognition and treatment planning of the prospective etiological factors are important for proper diagnosis and treatment planning. There is no pin-point confirmation for authentic, inevitable and successful treatment strategies for these abfraction lesions.

\section{References}

1. Lee WC, Eakle WS (1984) Possible role of tensile stress in the etiology of cervical erosive lesions of teeth. J Prosthetic Dent 52: 374-80.

2. Braem M, Lambrechts P, Vanherle G (1992) Stress-induced cervical lesions. J Prosthet Dent 67: 718-22.

3. Grippo JO (1991) Abfractions: a new classification of hard tissue lesions of teeth. J Esthet Dent 3: 14-9.

4. Rees JS, Jagger DC (2003) Abfraction lesions: myth or reality? J Esthet Restor Dent 15: 263-71.

5. Tomsaik M (2006) Analysis of etiological factors involved in non carious cervical lesions. Ann Acad Med Stetin 52: 125-36.

6. Mjor IA (2001) Pulp-dentin biology in restorative dentistry. Part 5: clinical management and tissue changes associated with wear and trauma. Quintessence Int 32: 771-788.

7. Bartlett DW, Shah P (2006) A critical review of non-carious cervical (wear) lesions and the role of abfraction, erosion, and abrasion. J Dent Res 85: 306-312.

8. Michael JA, Townsend GC, Greenwood LF, Kaidonis JA (2009) Abfraction: separating fact from fiction. Aust Dent J 54: 2-8.

9. Grippo JO, Simring M, Coleman TA (2012) Abfraction, abrasion, biocorrosion, and the enigma of noncarious cervical lesions: a 20 -year perspective. J Esthet Restor Dent 24: 10-23.

10. Aw TC, Lepe X, Johnson GH, Mancl L (2002) Characteristics of noncarious cervical lesions: a clinical investigation. J Am Dent Assoc 133: 725-733.

11. Lee WC, Eakle WS (1996) Stress-induced cervical lesions: review of advances in the past 10 years. J Prosthet Dent 75: 487-494.
12. Levitch LC, Bader JD, Shugars DA, Heymann HO (1994) Non-carious cervical lesions. J Dent 22: 195-207.

13. Mayhew RB, Jessee SA, Martin RE (1998) Association of occlusal, periodontal, and dietary factors with the presence of non-carious cervical dental lesions. Am J Dent 11: 29-32.

14. Bader ID, Shugars DA (2008) Variation in clinical decision making related to caries. In: Fejerskov O, Kidd E, editors. Dental Caries: The Disease and Its Clinical Management. 2nd ed. Copenhagen: Blackwell Munksgaard Ltd: 555-574.

15. Ichim IP, Schmidlin PR, Li Q, Kieser JA, Swain MV (2007) Restoration of non-carious cervical lesions part II. Restorative material selection to minimise fracture. Dent Mater 23: 1562-1569.

16. Antonelli JR, Hottel TL, Garcia-Godoy F (2013) Abfraction Lesions Where do They Come From? A Review of the Literature. J Tenn Dent Assoc 93: 14-19.

17. Lee HE, Lin CL, Wang CH, Cheng CH, Chang CH (2002) Stresses at the cervical lesion of maxillary premolar - a finite element investigation. J Dent 30: 283-290.

18. Rees JS (2006) The biomechanics of abfraction. Proc Inst Mech Eng $\mathrm{H}$ 220: 69-80.

19. Silva AG, Martins CC, Zina LG (2013) The association between occlusal factors and noncarious cervical lesions: a systematic review. J Dent 41 : 9-16.

20. Sarode, Gargi S, Sarode, Sachin C (2013) Abfraction: A review. Journal of Oral and Maxillofacial Pathology 17: 222-227.

21. Shetty SM, Shetty RG, Mattigatti S, Managoli NA, Rairam SG (2013) No Carious Cervical Lesions. J Int Oral Health 5: 142-145.

22. Lynch CD, O'Sullivan VR, Dockery P, McGillycuddy CT, Sloan AJ (2010) Hunter-Schreger Band patterns in human tooth enamel. J Anat 217: 106-115.

23. Rees JS, Hammadeh M, Jagger DC (2003) Abfraction lesion formation in maxillary incisors, canines and premolars: a finite element study. Eur J Oral Sci 111: 149-154.

24. Hammadeh M, Rees JS (2001) The erosive susceptibility of cervical versus occlusal enamel. Eur J Prosthodont Restor Dent 9: 13-17.

25. McCoy G (1982) The etiology of gingival erosion. J Oral Implantol 10: 361-362.

26. McCoy G (1983) On the longevity of teeth. J Oral Implantol 11: 248-267.

27. Wood ID, Kassir AS, Brunton PA (2009) Effect of lateral excursive movements on the progression of abfraction lesions. Oper Dent 34: 273-279.

28. Pintado MR, Delong R, Ko CC, Sakaguchi RL, Douglas WH (2000) Correlation of noncarious cervical lesion size and occlusal wear in a single adult over a 14-year time span. J Prosthet Dent 84: 436-443.

29. Estafan A, Furnari PC, Goldstein G, Hittelman EL (2005) In vivo correlation of noncarious cervical lesions and occlusal wear. J Prosthet Dent 93: 221-226.

30. Wada I, Shimada Y, Ikeda M (2015) Clinical assessment of non carious cervical lesion using swept-source optical coherence tomography. J Biophotonics 8: 846-854.

31. Hur B, Kim HC, Park JK, Versluis A (2011) Characteristics of non-carious cervical lesions - an ex vivo study using micro computed tomography. Journal of Oral Rehabilitation 38: 469-74.

32. Dejak B, Młotkowski A, Romanowicz M (2003) Finite element analysis of stresses in molars during clenching and mastication. Journal of Prosthetic Dentistry 90: 591-7.

33. Borcic J, Anic I, Smojver I, Catic A, Miletic I (2005) 3D finite element model and cervical lesion formation in normal occlusion and in malocclusion. Journal of Oral Rehabilitation 32: 504-10.

34. Grippo JO, Simring M, Schreiner S (2004) Attrition, abrasion, corrosion and abfraction revisited: a new perspective on tooth surface lesions. J Am Dent Assoc 135: 1109-1118.

35. Paryag A, Rafeek R (2014) Dental erosion and medical conditions: an overview of aetiology, diagnosis and management. West Indian Med J 63: 499-502. 
Citation: El-Marakby AM, Al-Sabri FA, Alharbi SA, Halawani SM, Yousef MTB (2017) Noncarious Cervical Lesions as Abfraction: Etiology, Diagnosis, and Treatment Modalities of Lesions: A Review Article. Dentistry 7: 438. doi:10.4172/2161-1122.1000438

Page 6 of 6

36. Hur B, Kim HC, Park JK, Versluis A (2011) Characteristics of non-carious cervical lesions - an ex vivo study using micro computed tomography. J Oral Rehabil 38: 469-474.

37. Mjor IA, Sveen OB, Heyeraas KJ (2001) Pulp-dentin biology in restorative dentistry. Part 1: normal structure and physiology. Quintessence Int 32: 427-446.

38. Kaidonis JA, Richards LC, Townsend GC (2005) Non-carious changes to tooth crowns. In: Mount GJ, Hume WR, editors. Preservation and Restoration of Tooth Structure. 2nd ed. Varsity Lakes, QLD: Varsity Lakes: 47-60.

39. Smith BG, Knight JK (1984) An index for measuring the wear of teeth. Br Dent J 156: 435-438.

40. Loomba K, Bains R, Bains VK, Loomba A (2014) Proposal for clinical classification of multifactorial noncarious cervical lesions. Gen Dent 62: 39-44.

41. Brackett WW, Dib A, Brackett MG, Reyes AA, Estrada BE (2003) Twoyear clinical performance of Class $\mathrm{V}$ resin-modified glass-lonomer and resin composite restorations. Oper Dent 28: 477-481.

42. Wood I, Jawad Z, Paisley C, Brunton P (2008) Non-carious cervical tooth surface loss: a literature review. J Dent 36: 759-766.

43. Duke ES, Lindemuth J (1990) Polymeric adhesion to dentin: contrasting substrates. Am J Dent 3: 264-270.

44. Piotrowski BT, Gillette WB, Hancock EB (2001) Examining the prevalence and characteristics of abfractionlike cervical lesions in a population of U.S. veterans. J Am Dent Assoc 132: 1694-1701.

45. Jena A, Shashirekha G (2015) Comparison of efficacy of three different desensitizing agents for in-office relief of dentin hypersensitivity: a 4 weeks clinical study. J Conserv Dent 18: 389-393.

46. Baysan A, Lynch E (2003) Treatment of cervical sensitivity with a root sealant. Am J Dent 16: 135-138.

47. Sharif MO, Iram S, Brunton PA (2013) Effectiveness of argininecontaining toothpastes in treating dentine hypersensitivity: a systematic review. J Dent 41: 483-492.
48. Beddis H, Soneji P, Welford S, Ashley M (2013) Making sense of sensitivity. Dent Update 40: 403-404.

49. Petersson LG (2013) The role of fluoride in the preventive management of dentin hypersensitivity and root caries. Clin Oral Investig 17: 63-71.

50. Sgolastra F, Petrucci A, Severino M, Gatto R, Monaco A (2013) Lasers for the treatment of dentin hypersensitivity: a meta-analysis. J Dent Res 92: 492-499.

51. Powell LV, Gordon GE, Johnson GH (1990) Sensitivity restored of Class V abrasion/erosion lesions. J Am Dent Assoc 121: 694-696.

52. Lambrechts P, Van Meerbeek B, Perdigao J, Gladys S, Braem M (1996) Restorative therapy for erosive lesions. Eur J Oral Sci 1042: 229-240.

53. Francisconi LF, Graeff MS, Martins Lde M (2009) The effects of occlusal loading on the margins of cervical restorations. J Am Dent Assoc 140: 1275-1282.

54. Brackett WW, Robinson PB (1990) Composite resin and glass-ionomer cement: current status for use in cervical restorations. Quintessence Int 21: 445-447.

55. Heymann HO, Sturdevant JR, Bayne S, Wilder AD, Sluder TB (1991) Examining tooth flexure effects on cervical restorations: a two-year clinical study. J Am Dent Assoc 122: 41-47.

56. Osborne-Smith KL, Burke FJ, Wilson NH (1999) The aetiology of the non-carious cervical lesion. Int Dent J 49: 139-143.

57. Peumans M, De Munck J, Mine A, Van Meerbeek B (2014) Clinical effectiveness of contemporary adhesives for the restoration of noncarious cervical lesions. A systematic review. Dent Mater 30: 1089-1103.

58. Tyas MJ (1995) The Class V lesion - aetiology and restoration. Aust Dent J 40: 167-170.

59. Smales RJ, Ng KK (2004) Longevity of a resin-modified glass ionomer cement and a polyacid-modified resin composite restoring non-carious cervical lesions in a general dental practice. Aust Dent J 49: 196-200.

60. Heintze SD, Roulet JF (2010) Glass ionomer derivates have better retention rates in cervical restorations compared to self-etching adhesive systems. J Evid Based Dent Pract 10: 18-20. 